\title{
Tissue Engineered Trachea Using Decellularized Aorta
}

Ana C. Paz1, Koji Kojima', Kiyotaka Iwasaki', Jason D. Ross' ${ }^{1}$, Jose A. Canseco ${ }^{1}$, Mitsuo Umezu' and Charles A Vacanti'

${ }^{1}$ Laboratory for Tissue Engineering and Regenerative Medicine, Brigham \& Women's Hospital, Harvard Medical School

${ }^{2}$ Waseda Institute for Advanced Study.Center for Advanced Biomedical Sciences, Waseda University, Japan

\begin{abstract}
Background: Several approaches for the development of tracheal substitutes for the treatment of extensive tissue defects have been explored over the years. However, a completely satisfactory approach has not been achieved. Previously, we described a composite tissue engineered trachea (TET) using chondrocytes seeded onto a polyglycolic acid (PGA) fiber-mesh. This study was considered to improve the design and functionality of the TET by using a porcine decellularized aorta as the scaffold.
\end{abstract}

Methods: Chondrocytes were harvested from sheep tracheal cartilage and were suspended in medium. The chondrocytes were then seeded onto PGA and incubated in vitro for 1 week. A $3 \times 4 \mathrm{~cm}$ piece was cut from a decellularized aorta and four $0.5 \times 3 \mathrm{~cm}$ pieces were excised from one side in a comb like fashion. A silicon stent was inserted into this structure and the spaces were filled with chondrocyte seeded PGA. The three dimensional cell-polymer construct was then implanted into a subcutaneous pocket of a nude rat for 4 weeks. Both native and TET were analyzed for sulfated glycosaminoglycan (S-GAG) and hydroxyproline content, and stained for H\&E, Safranin-O and Collagen TypeII antibody.

Results: The improved design of TET formed new cartilage rings in the structuralconfiguration of native trachea. Furthermore, the decellularized aorta connected well to the cartilage, which provided an excellent support to the rings, as well as good flexibility to the engineered trachea. Histological evaluation of TET showed the presence of mature cartilage. S-GAG and hydroxyproline content was similar to native cartilage levels.

Conclusion: This study demonstrates the feasibility of engineering a trachea with defined cartilage rings and similar flexibility to the native trachea.

Keywords: Airway; Bioengineering; Cell biology/culture; Tissue Engineering; Trachea

\section{Introduction}

Experimental and clinical tracheal, bronchial repair or anastomosis began in the late $19^{\text {th }}$ century [1]. Since then the technique of tracheal reconstruction by end-to-endanostomosis has been used in a variety of tracheal diseases, such as stenosis,tracheomalacia, tuberculosis, traumatic injury, and malignancies [2]. However, this established method is not appropriate for the repair of extensive lesions. Therefore, for these types of lesions other replacement methods, such as autografts $[2,3]$, allografts $[4,5]$, prosthetics materials [6-8] and tissue engineering [9-12] have been studied and developed. Some partial successes have been announced with some of these methods, butso far not one of them has archived a completely satisfactory long-term tracheal replacement for extensive lesions of the trachea.

Tissue engineering is an interdisciplinary field that applies the principles of engineering and life science toward the development of biological substitutes that restore, maintain, orimprove tissue function [13]. The last decade of the $20^{\text {th }}$ century saw an influx of newresearch concepts in terms of tissue engineering, which has had a revolutionary impact on the research of tracheal prosthesis [14]. In 1994 two of the first reports on the effort to engineer a trachea were made by Osada and colleagues [9] and Vacanti and colleagues [10]. With different approaches, both groups were trying to recreate the cylindrical shape of the trachea, combining material and cells to make a more biocompatible tracheal replacement. Our group believes that the requirements for an ideal TET are: (1) easy,less-invasive harvest procedure that yields sufficient cells in a relatively short time, (2) abiocompatible and biodegradable scaffolding that avoids inflammatory responses, (3) proper flexibility and stiffness, (4) air tightness, (5) neovascularization,
(6) epithelial regeneration and (7) growth on the insert, which is especially important in the treatment of pediatric patients [15].

Scaffolds derived from xenogenic extracellular matrix have been used in numerous tissue-engineering applications [16]. These types of scaffolds are obtained by removing the cellular components of the tissues through different methods. The most effective method for the decellularization of tissues includes a combination of physical, chemical and enzymatic approaches [17]. In an optimal decellularization process, cells have to be completely removed from the tissue while preserving the components of the extracellular matrix $[17,18]$. Porcine extracellular matrix from different tissues, such as valves $[18,19]$, urinary bladder [16] and small intestinal submucosa SIS [20,21], have yielded positive results when used as a scaffold for tissue repair.

Previously, our group demonstrated the feasibility to engineer a trachea using tissue engineered cartilage and epithelium from different cells sources and with various biomaterials, such as PGA or Pluronic[11,22,23]. The present study is considered to have improved

*Corresponding author: Koji Kojima, MD, PhD, Laboratory for Tissue Engineering and Regenerative Medicine, Department of Anesthesiology, Brigham \& Women's Hospital, Harvard Medical School, 75 Francis St. Thorn 1327 Boston, MA, 02115 , USA, Tel: 617732 5863; Fax: 617975 0884; E-mail: kojima@zeus.bwh.harvard. edu

Received December 01, 2011; Accepted December 08, 2011; Published December 09, 2011

Citation: Paz AC, Kojima K, Iwasaki K, Ross JD, Canseco JA, et al. (2011) Tissue Engineered Trachea Using Decellularized Aorta. J Bioengineer \& Biomedical Sci S2:001. doi:10.4172/2155-9538.S2-001

Copyright: (C) 2011 Paz AC, et al. This is an open-access article distributed unde the terms of the Creative Commons Attribution License, which permits unrestricted use, distribution, and reproduction in any medium, provided the original author and source are credited. 
Citation: Paz AC, Kojima K, Iwasaki K, Ross JD, Canseco JA, et al. (2011) Tissue Engineered Trachea Using Decellularized Aorta. J Bioengineer \& Biomedical Sci S2:001. doi:10.4172/2155-9538.S2-001

Page 2 of 7

the design and functionality of the tissue engineered trachea by using aporcine decellularized aorta as a scaffold providing structural support, so as to create a tracheal tube with defined C-shape cartilage rings.

\section{Materials and Methods}

\section{Chondrocytes isolation and culture}

Samples of sheep tracheal cartilage $(\mathrm{n}=6)$, two to three tracheal rings, were obtained from 2 months-old sheep. To isolate chondrocyte cells, each sample was digested with $0.3 \%$ collagenase type II (Worthington Biochemical Corp. Freehold, NJ, USA) at $37^{\circ} \mathrm{C}$ for $5-7$ hours while shaking. Chondrocytes were cultured in Ham's F-12 media (Gibco, GranIsland, NJ) containing 10\% fetal calf serum (Gibco, Gran Island, NJ) with $292 \mu \mathrm{g} / \mathrm{mL}$ Lglutamine, 10,000 U/mL penicillin G, 10,000 U/ $\mathrm{mL}$ streptomysin sulfate, $25 \mu \mathrm{g} / \mathrm{mLamphotericin} \mathrm{B}$, and $25 \mu \mathrm{g} / \mathrm{mL}$ ascorbic acid for 2 weeks. Culture medium was changed every 3 days. After 2 weeks, chondrocyte cells were trypsinized with $0.05 \%$ Trypsin EDTA (Gibco, Gran Island, NJ) at $37^{\circ} \mathrm{C}$ for $3 \mathrm{~min}$. Isolated cells were counted using a hematocytometer and the viability was determined using the trypan blue (Sigma-Aldrich,Irvine, CA) exclusion method.

\section{Cell seeding and implantation}

After trypsinization, suspensions of approximately $100 \times 106$
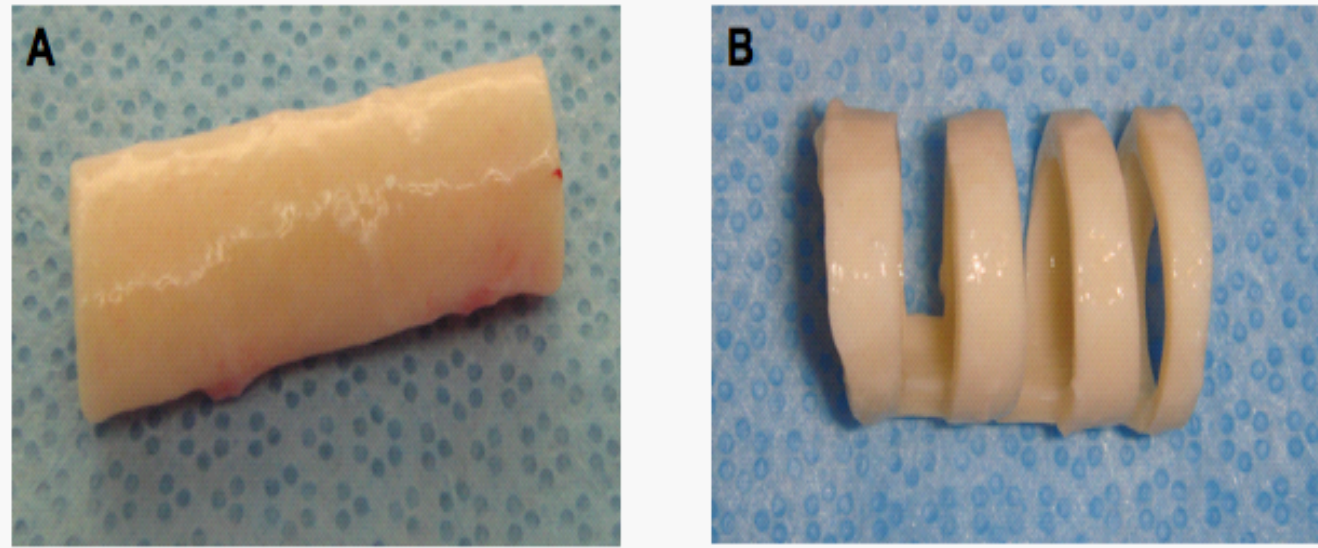

cell/ml was obtained. Each suspension was seeded onto $60 \times 50 \times 2$ mm matrix of non-woven PGA fiber meshpolymer. The cell-polymer constructs were incubated in-vitro for 1 week. Subsequently, 6 pieces of $3 \times 4 \mathrm{~cm}$ were cut from a porcine decellularized aorta (Figure 1A) and four $0.5 \times 3 \mathrm{~cm}$ pieces were excised from one side in a comb like fashion from each piece (Figure 1B). A $4 \mathrm{~cm}$ silicon tube stent was inserted into each of the decellularized aortas (Figure 1C) and the spaces were filled with chondrocyte-seeded PGA to create the tracheal rings (Figure 1D). Three-dimensional cell-polymer-aorta constructs were then implanted into a subcutaneous pocket of 6 nude rats for 4 weeks.

\section{Porcine aorta decellularization}

Porcine aortas were decellularized using a unique device for tissue-decellularization (Figure 2A). The device was developed by Dr. Iwasaki and his colleagues at the WasedaInstitute of Advanced Study, in Tokyo, Japan [19]. The device consists of a microwave irradiation unit and pulsatile circulation system. A porcine aorta with a length of $5 \mathrm{~cm}$ and a diameter of $16 \mathrm{~mm}$ was connected to a supporting chamber at both ends and incorporated into a pulsatile circulation system. Deoxycholic acid detergent with a concentration of $1 \mathrm{wt} \%$ was circulated. In parallel, a microwave at the frequency of $2.45 \mathrm{GHz}$ was irradiated. In order to prevent degeneration of extracellular matrix by heat generated by the microwaves, a cooling system for the working
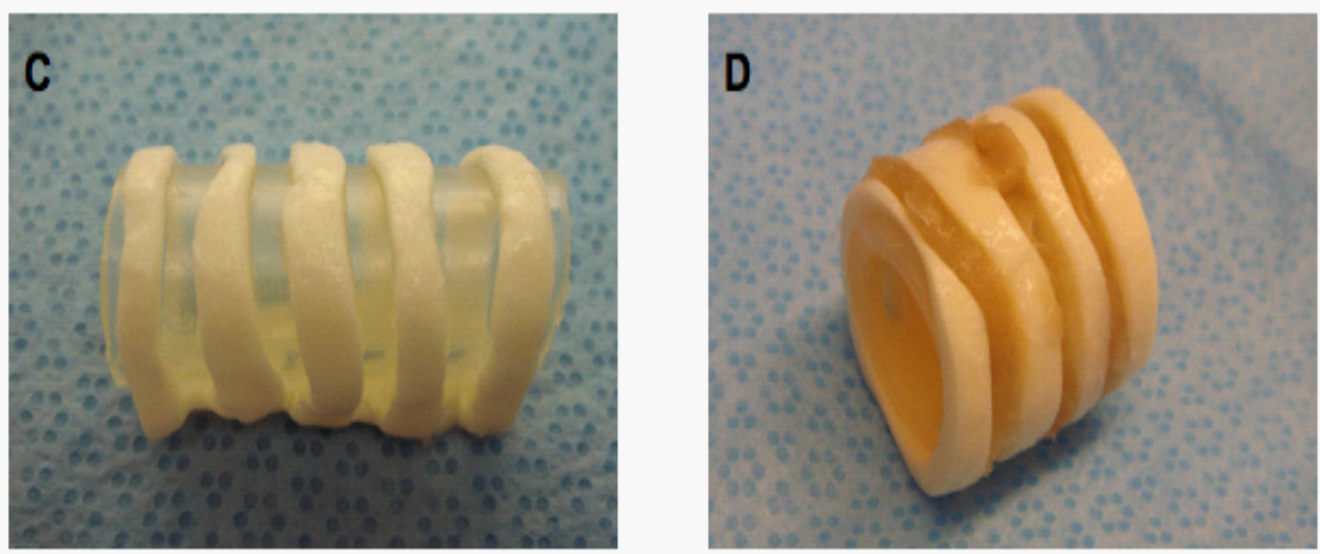

Figure 1: Appearance of the decelliularized porcine aorta (A). Sections of the decellularized aorta were excised in a comb like fashion (B). Silicon stents were placed inside the sectioned decellularized aorta (C). The spaces were filled with chondrocyte seeded PGA (D). 
fluid was equipped in the system. The temperature of the circulating detergent was monitored and regulated below $37^{\circ} \mathrm{C}$ using a feedback control mechanism throughout the period of decellularization. Porcine aortic tissue was aseptically harvested. The six aorta pieces were treated with the microwaves for a total of 24 hours in the pulsatile pressure and flow environment (Figure 2B).

\section{Histological examination}

Samples of TET and native trachea were fixed in $10 \%$ phosphatebuffered formalin,embedded in paraffin and sectioned. Sections were stained with H\&E, Safranin-O and anti-Collagen Type II antibody.

\section{Fluorescent immunohistochemistry or Immunofluorescence of collagen Type II antibody}

Paraffin sections of TET and native trachea were heated at $60^{\circ} \mathrm{C}$ for $10 \mathrm{~min}$ and rehydrated with Xylene and decreasing concentrations of Ethanol in water. Subsequently,tissue was permeabilized in $1 \mathrm{mg} / \mathrm{ml}$ of Pepsin (Sigma, St Louis, MO) in $10 \mathrm{mM}$ Tris HCL for 1.5 hours at $37^{\circ} \mathrm{C}$ and blocked with $10 \%$ rabbit serum (Jackson Immunoresearch,West Grove, PA). Incubation with the first antibody, anti-collagen type II (1/50,Chemicon, Temecula, CA), was carried overnight. Control slides were not exposed to the first antibody; instead they were incubated overnight with just the blocking solution. The visualization of the first antibody was made with anti-mouse IgG Texas Red (1/100,Jackson Immunoresearch, West Grove, PA). Cell nucleus was counter stained with 4', 6-Diamidino-2-phenyindole, dilactate, DAPI (Sigma, St Louis, MO). Finally, tissue was dehydrated with different concentrations of Ethanol and Xylene and covered with Xylene based media.

\section{Biochemical assay}

Due to the fact that proteoglycans and collagen type II are the main components of thecartilage extracellular matrix (ECM), it is important that the TET and the native tracheal rings have similar amounts of these components. The amount of proteoglycans was calculated measuring the amount of S-GAG, which form chain(s) that are attached through covalent bonding to a core protein to form proteoglycans. Additionally, the amount of collagen type II was calculated measuring the amount of Hydroxyproline, which is a major component of the collagen type II protein.

Biochemical analyses were performed on harvested tissue engineered $(n=6)$ and native trachea cartilage $(n=6)$ to quantify and compare the level of cartilage specific ECM components. First, around $30 \mathrm{mg}$ of each sample was measured and placed to dry out for 24 hours in a Vacuum Desiccator using Drierite (W.A. HAMMOND DRIERITE CO.LTD., Xenia, $\mathrm{OH}$ ) as a drying agent. Then, samples were weighted again and were digested for 16 hours at $60^{\circ} \mathrm{C}$ in $1 \mathrm{ml}$ of Papain solution, which contained $100 \mathrm{mM}$ sodium phosphate (Na2HPO4), $10 \mathrm{mM}$ sodium EDTA (Na2EDTA), $10 \mathrm{mM}$ cysteine hydrochloride (Sigma, St Louis, MO), $5 \mathrm{mM}$ EDTA, and $125 \mathrm{mg} / \mathrm{mL}$ papain (Sigma, StLouis, MO). Finally, the digested samples were stored at $-20^{\circ} \mathrm{C}$. S-GAG content of the digested samples was quantified with the Blycan Assay kit (Biocolor Ltd., Belfast, North Ireland). Briefly, $1 \mathrm{ml}$ of Blycan Dye Reagent, composed of 1,9-dymethyl-methylene blue in an inorganic buffer, was added to each digested sample. After 30 min the Blycan Dye Reagent bonded to S-GAG. Samples were centrifuged at $>10000 \mathrm{~g}$ for $10 \mathrm{~min}$ and the supernatant was removed. $1 \mathrm{ml}$ of Blycan Dissociation Reagent, which dissociates the S-GAGdye complex, was added to each sample. Absorbance was measured at $656 \mathrm{nmwith}$ a spectrophotometer. The S-GAG content of each sample was determined by reading the concentration in the standard curve. Hydroxyproline content of the digested samples was determined by the procedure of Stegemann and Stadler [24]. Briefly, the digested samples were hydrolyzed with equal volumes of $6 \mathrm{~N} \mathrm{HCL}$ at $115^{\circ} \mathrm{C}$ for 16 hours.Chloramine $\mathrm{T}$ and p-dimethyl amino-benzaldehyde were added to the hydrolyzed samples; absorbance was measured at $560 \mathrm{~nm}$ with a spectrophotometer immediately after addition of the dye. The hydroxyproline content of each sample was determined by reading the concentration in the standard curve. Means and standard deviations
A

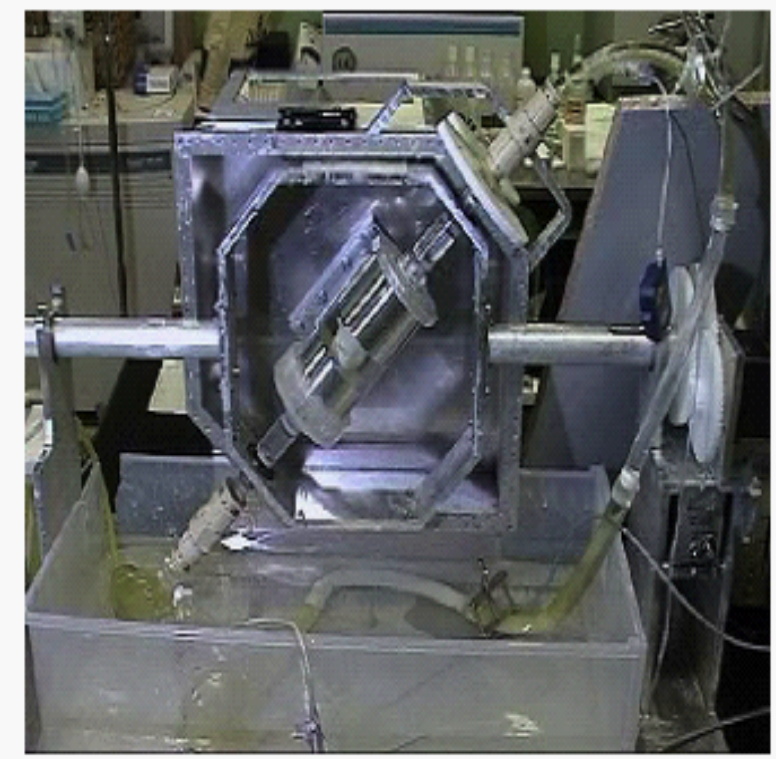

B

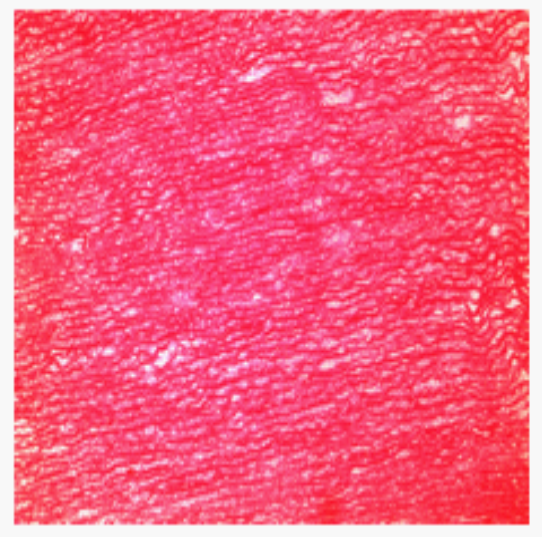

Decellularized Aorta.

Figure 2: Novel device used to decellularize the sections of porcine aortas (A). $\mathrm{H}$ and Estaining of decelliularized porcine aorta (B). 

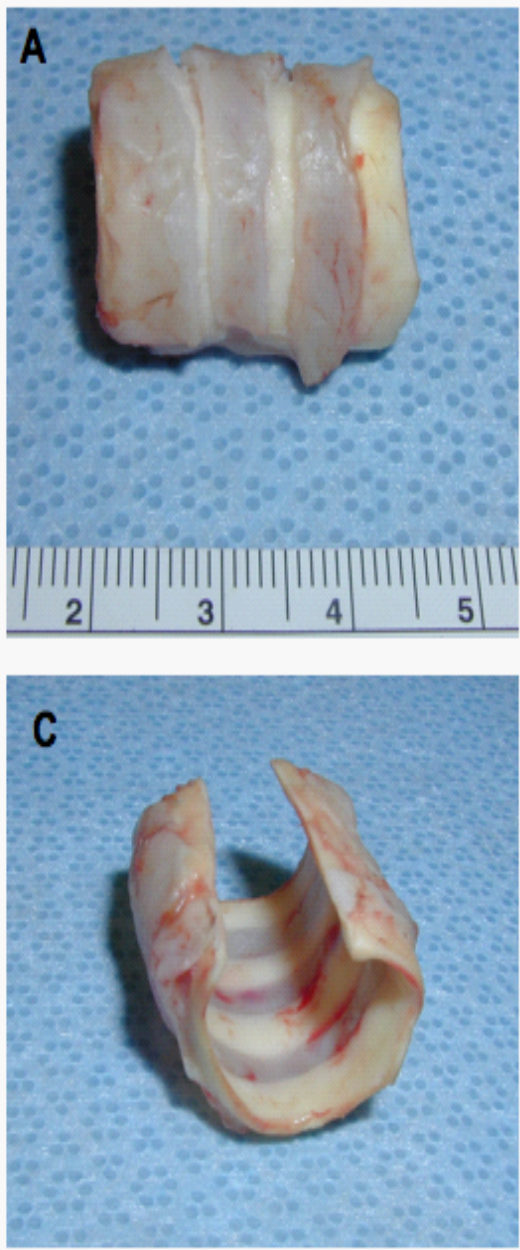
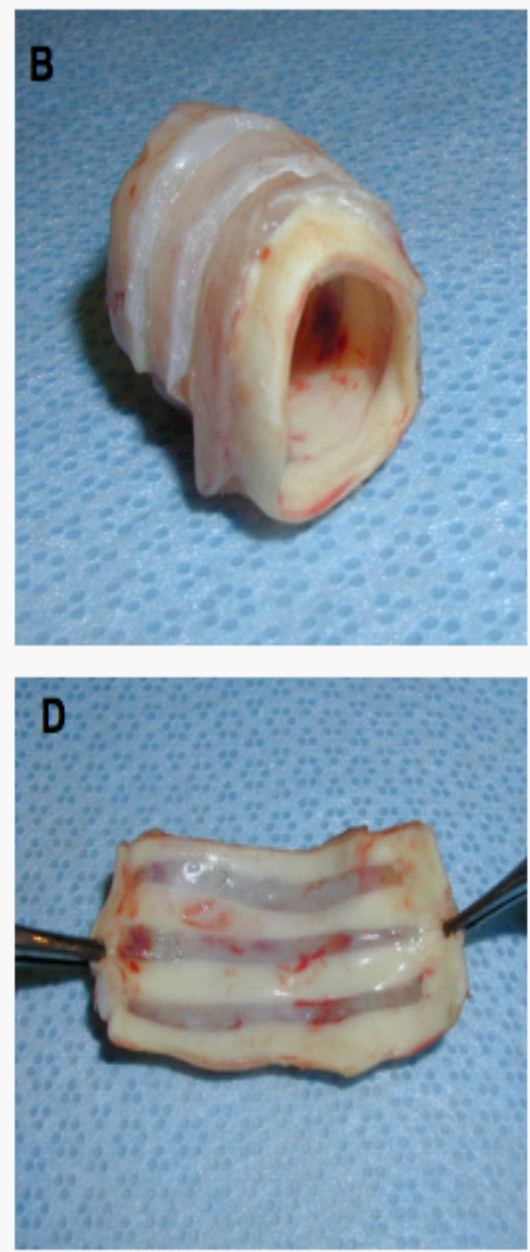

Figure 3: Appearance of tissue engineered trachea following 4 week harvest, Lateral view $(A)$, frontal view $(B)$ and inside view $(C, D)$.

A

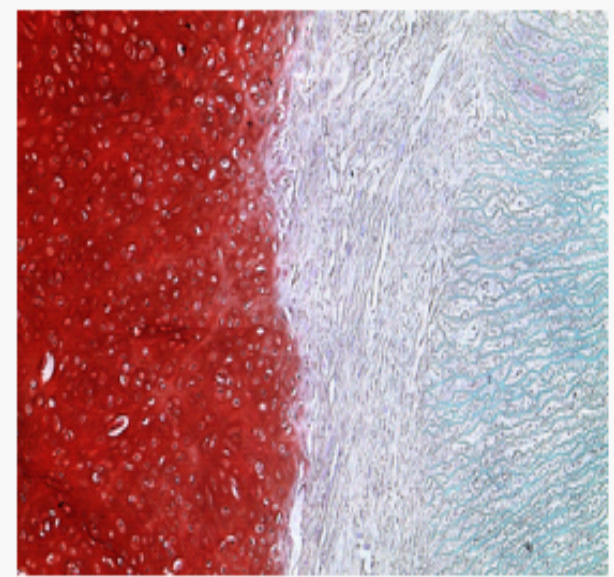

Safranin -0
B

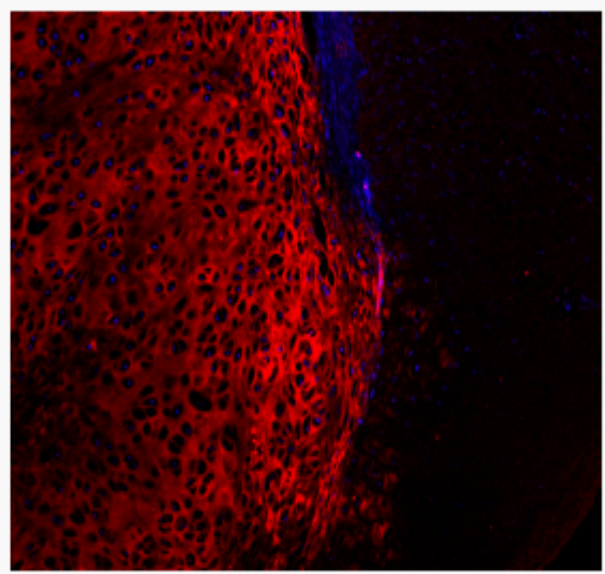

Collagen Type II

Figure 4: Safranin-O stains demonstrating were deeply positive and indicate of abundant protepglycan production (A). Immunostaining with Collagen type II antibody reveled its existence in the TET cartilage $(B)$. 
were calculated for each assay. Statistical significance was determined with a Welch's t-test.

\section{Results}

\section{Gross morphology}

After 4 weeks, the three-dimensional cell-polymer-aorta constructs formed a TET with defined C-shape cartilage rings, which visibly recreated the structure of a normal trachea (Figure $3 \mathrm{~A}, \mathrm{~B}$ ). The decellularized aorta appeared intact and well integrated to the de novocartilage, thus the entire construct felt firm and stable to the touch, and seemed to have adequate stiffness (Figure 3 C,D). Finally, the decellularized aorta appeared to provide appropriate support to the tracheal cartilage.

\section{Histology assay}

Histological examination of the specimens showed evidence of the formation of mature cartilage in the TET cartilage, and the decellularized aorta connected well with the denovo cartilage. Hematoxyline and Eosin (H\&E) staining revealed a resemblance of themicroscopic morphology in TET cartilage to that of normal hyaline cartilage, and showed the decellularized aorta without infiltration of any type of cells. Safranin-O staining demonstrated the present of proteoglycans in the ECM of both TET and native trachealcartilage (Figure 4A). Finally, immunostaining for Collagen type II antibody in TET and native tracheal cartilage was predominant in both ECMs and also showed the de novocartilage did not invade the decellularized aorta (Figure 4B).

\section{Biochemical assay}

S-GAG and Hydroxyproline content in TET were not statistically significantly different to native tracheal cartilage levels. S-GAG content of the TET cartilage was $33.31 \mu \mathrm{g} / \mathrm{mg} \pm 6.26 \mu \mathrm{g} / \mathrm{mg}$ and in native tracheal cartilage was $37.67 \mu \mathrm{g} / \mathrm{mg} \pm 3.14 \mu \mathrm{g} / \mathrm{mg}$ (Figure 5A).The Hydroxyproline content of the TET cartilage was $1.66 \mu \mathrm{g} / \mathrm{mg} \pm 0.54$ $\mu \mathrm{g} / \mathrm{mg}$ and in the native trachea cartilage was $2.19 \mu \mathrm{g} / \mathrm{mg} \pm 0.34 \mu \mathrm{g} / \mathrm{m}$. S-GAG and Hydroxyprolinecontent in TET cartilage was $88 \%(\mathrm{p}=0.17)$ and $75 \%(\mathrm{p}=0.08)$ of the native trachea cartilage respectively (Figure $5 B)$.

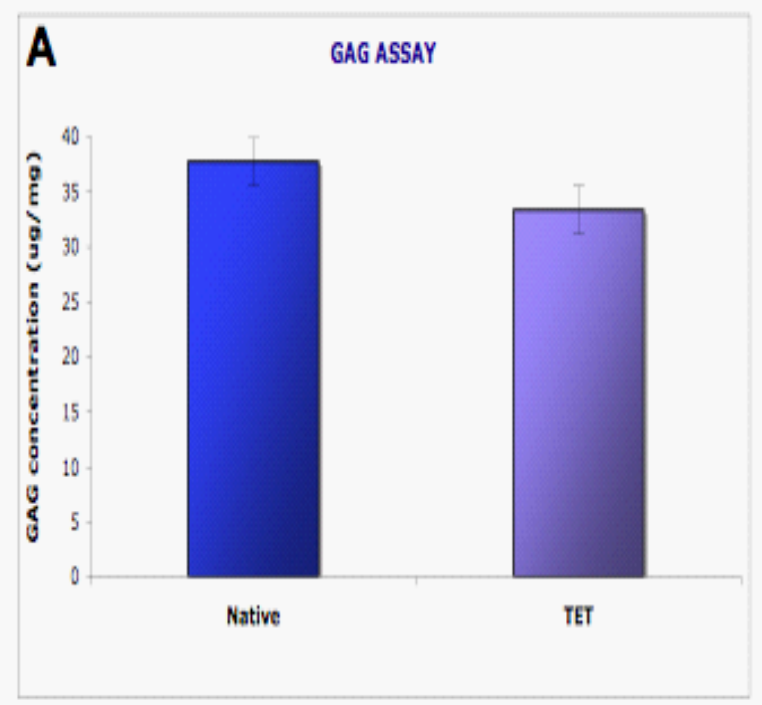

\section{Discussion}

Our group has previously demonstrated the feasibility of engineering a trachea using PGA, a thermo reversible hydrogel (pluronic F127) [22] and a thermo reversible gelation polymer (TGP) [26] alone. These past results showed mature and adequate engineered cartilage in a tracheal shape in an animal model with a T cell deficiency. When we moved on to creating an autologous model in vivo in an immunocompetent host, the chondrocytes seeded on PGA, Pluronic F127 or TGP were sufficient for creating healthy cartilage. However, the tissue did not hold a proper tracheal shape due to the lack of sufficient glycosaminoglycan and collagen content. This was likely due to the development of a strong inflammatory response or perhaps because the gelatinous consistency of Pluronic F127 and TGP is poor at maintaining a proper shape. To attempt to circumvent the effects of inflammation, we experimented with the use of an anti-inflammatory drug during the implantation period, but the results showed no significant differences to those without the use of anti-inflammatory agents. Moreover, the tissue generated in the autologous immunocompetent model did not demonstrate sufficient engineered tracheal cartilage using either, PGA, Pluronioc F127 and TGP. Thus, we hypothesized that using an alternative material that led to a reduced or absent inflammatory response would generate improved tracheal cartilage. This belief guided our group to focus on using aorta because of its flexibility, and similar size and tubular shape to the human trachea. However, as shown by Tsukada and colleagues [26], using an aortic allograft alone for tracheal replacement leads to necrosis with calcifications or connective tissue replacement of the allograft. Furthermore, the allograft showed no signs of angiogenesis or even evidence of tracheal cartilage regeneration. Finally, the $8 \mathrm{~cm}$ aortic allografts shortened up to $87.5 \%$ when used for tracheal replacement.

Therefore, based on our previous results, our group concluded that a combination of cell and polymer with a decellularized aortic scaffold would be able to prevent the generation of a strong inflammatory response, avoid necrosis, calcification and contraction, improve overall tracheal cartilage regeneration and structure, and enhance the angiogenic response.

Current decellularization protocols that have become standard are based on $0.1 \%$ sodiumdodecyle sulfate (SDS) or $3 \%$ Triton X-100

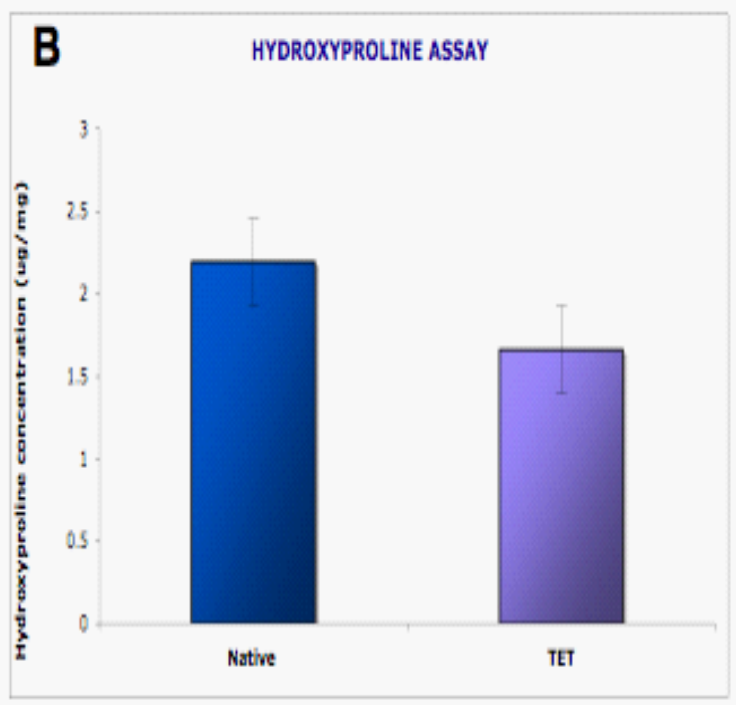

Figure 5: Biochemical assays. GAG (A) and Hydroxyproline (B) content in TET. No statistically significantly different was determined by a Welch's t-test. 
(tert-octylphenylpolyoxyethylen). However,this detergent-based methods sacrifice the mechanical integrity of the underlying ECM. It has been reported that ECM damage is due to collagen fibers becoming more loosely packed following decellularization due to the loss of glycosaminoglycans, thus there populated decellularized material does not have the same mechanical strength in vivo [28-30].

Our new decellularization method consists of a microwave irradiation unit along with apulsatile circulation system. It treats aortas with microwave irradiation enhancing the immersion of detergent into the thick aortic tissue by its resonance effect on water molecules. This then leads to the cell membranes being dissolved, causing less damage to collagen fibers. As a result, the unique decellularization method used in this study has advantages in preserving mechanical integrity while dissolving cell membranes. A previous study on this decellularization method demonstrated that it allows the preservation of the ultimate strength and elastic modulus of decellularized aortic valve leaflets and aorta, both results comparable to untreated controls [19].

Based on the success of this novel decellularization method, our group conceived the idea of using a decellularized aortic graft as a flexible support structure for our engineered cartilage created from a PGA scaffold. Our results from this study show that we engineered mature rigid cartilage tissue in between the decellularized aortic graft, generating a well-connected TET with no obstructions. Thus, by creating a cell-polymer decellularized aortic graft construct we were able of engineering a construct withenhanced structural support.

Of note, in this initial study in a nude rat model we were unable to reconstitute the pseudostratified columnar, ciliated epithelium native to the trachea. However, our group has demonstrated that wrapping of an injured deepithialized trachea with an external epithelial/ endothelial cell sheet provided the tissue with similar or enhanced benefits as a native luminal epithelial layer [31]. Thus, when moving to an autologous immunocompetent model, we plan to wrap the engineered tissue and decellularized graft construct with an epithelial and/or endothelial cell sheet to provide the construct with a means to control injury and fibrous response, and preserve tissue perfusion, leading to an enhanced overall reparative response.

In conclusion, our study has demonstrated the feasibility of creating a structurally soundtissue engineered tracheal replacement by combining chondrocytes seeded on a PGA scaffold with a decellularized aortic scaffold. By using the aorta as a backbone, our group was able to improve the structural stability of the regenerated cartilage, and generate tissue strikingly similar to native cartilage. The next step is to repeat the study in an autologous immunocompetent animal model, and examine the tissue histologically aswell as biomechanically. The ultimate goal is to optimize our novel technique with the hopes of providing a new therapy for patients with extensive tracheal disease.

\section{References}

1. Grillo HC (2002) Tracheal replacement: a critical review. Ann Thorac Surg 73 1995-2004.

2. Martinod E, Seguin A, Pfeuty K, Fornes P, Kambouchner M, et al. (2003) Longterm evaluation of the replacement of the trachea with an autologous aortic graft. Ann Thorac Surg: 75: 1572-1578.

3. Cavadas PC, Bonanad E, Baena-Montilla P, Vera-Sempere FJ (1996) Prefabrication of a free flap for tracheal reconstruction: an experimental study. Preliminary report. Plast Reconstr Surg 98: 1052-1062.

4. Carbognani P, Spaggiari L, Solli P, Corradi A, Cantoni AM, et al. (1999) Experimental tracheal transplantation using a cryopreserved aortic allograft. Eur Surg Res 31: 210-215.
5. Conconi MT, De Coppi P, Di Liddo R, Vigolo S, Zanon GF, et al. (2005) Tracheal matrices, obtained by a detergent-enzymatic method, support in vitro the adhesion of chondrocytes and tracheal epithelial cells. Transpl Int 18: 727-734.

6. Neville WE (1982) Reconstruction of the trachea and stem bronchi with Neville prosthesis. Int Surg 67: 229-234.

7. Tsukada H, Osada $\mathrm{H}$ (2004) Experimental study of a new tracheal prosthesis: pored Dacron tube. J Thorac Cardiovasc Surg 127: 877-884.

8. Schultz P, Vautier D, Charpiot A, Lavalle P, Debry C (2007) Development of tracheal prostheses made of porous titanium: a study on sheep. Eur Arch Otorhinolaryngol 264: 433-438

9. Osada H, Takeuchi S, Kojima K, Yamate N (1994) The first step of experimental study on hybrid trachea: use of cultured fibroblasts with artificial matrix. J Cardiovasc Surg (Torino) 35: 165-168.

10. Vacanti CA, Paige KT, Kim WS, Sakata J, Upton J, et al. (1994) Experimenta tracheal replacement using tissue-engineered cartilage. J Pediatr Surg 29 201-204.

11. Kojima K, Bonassar LJ, Roy AK, Vacanti CA, Cortiella J (2002) Autologous tissue-engineered trachea with sheep nasal chondrocytes. J Thorac Cardiovasc Surg 123: 1177-1184

12. Weidenbecher M, Tucker HM, Awadallah A, Dennis JE (2008) Fabrication of a neotrachea using engineered cartilage. Laryngoscope 118: 593-598.

13. Langer R, Vacanti JP (2003) Tissue engineering. Science: 260: 920-926.

14. Kochneva ZV, Vabishchevich AV (1999) The anesthesiological aspects of the support for endoscopic manipulations on the tracheobronchial tree. Anestezio Reanimatol 48-50.

15. Kojima K, Vacanti CA (2004) Generation of a tissue-engineered tracheal equivalent. Biotechnol Appl Biochem 39: 257-262.

16. Badylak SF (2004) Xenogeneic extracellular matrix as a scaffold for tissue reconstruction. Transpl Immunol 12: 367-377.

17. Gilbert TW, Sellaro TL, Badylak SF (2006) Decellularization of tissues and organs. Biomaterials: 27: 3675-3683.

18. Schenke-Layland K, Vasilevski O, Opitz F, Konig K, Riemann I, et al. (2003) Impact of decellularization of xenogeneic tissue on extracellular matrix integrity for tissue engineering of heart valves. J Struct Biol 143: 201-208.

19. Iwasaki K, Ozaki S, Kawai T, Yamaguchi S, Eto M,et al. (2005): Innovative bioreactor technologies produced a completely decellularized and preendothelialized functional aortic valve, Proceedings of the 12th International Conference on Biomedical Engineering, 1A2-07, CD-ROM, ISSN: 1727-1983, ISBN:981-05-4572-X.

20. Brown B, Lindberg K, Reing J, Stolz DB, Badylak SF (2006) The basement membrane component of biologic scaffolds derived from extracellular matrix. Tissue Eng 12: 519-526.

21. Huber JE, Spievack A, Simmons-Byrd A, Ringel RL, Badylak S (2003) Extracellular matrix as a scaffold for laryngeal reconstruction. Ann Otol Rhino Laryngol 112: 428-433.

22. Kojima K, Bonassar LJ, Roy AK, Mizuno H, Cortiella J, et al. (2003) A composite tissue-engineered trachea using sheep nasal chondrocyte and epithelial cells. FASEB J 17: 823-828.

23. Kojima K, Ignotz RA, Kushibiki T, Tinsley KW, Tabata Y, et al. (2004) Tissueengineered trachea from sheep marrow stromal cells with transforming growth factor beta2 released from biodegradable microspheres in a nude rat recipient. J Thorac Cardiovasc Surg 128: 147-153.

24. Stegemann H, Stalder K (1967) Determination of hydroxyproline. Clin Chim Acta: 18: 267-273

25. Kheir E, Stapleton T, Shaw D, Jin Z, Fisher J, et al. (2011) Development and characterization of an acellular porcine cartilage bone matrix for use in tissue engineering. J Biomed Mater Res A 99: 283-294.

26. Yasuda A, Kojima K, Tinsley KW, Yoshioka H, Mori Y, et al. (2006) In vitro culture of chondrocytes in a novel thermoreversible gelation polymer scaffold containing growth factors. Tissue Eng 12: 1237-1245

27. Tsukada H, Ernst A, Gangadharan S, Ashiku S, Garland R, et al. (2010) Tracheal Replacement with a silicone-stented, fresh aortic allograft in sheep. Ann Thorac Surg: 89: 253-258 
Citation: Paz AC, Kojima K, Iwasaki K, Ross JD, Canseco JA, et al. (2011) Tissue Engineered Trachea Using Decellularized Aorta. J Bioengineer \& Biomedical Sci S2:001. doi:10.4172/2155-9538.S2-001

Page 7 of 7

28. Kheir E, Stapleton T, Shaw D, Jin Z, Fisher J, et al. (2011) Development and characterization of an acellular porcine cartilage bone matrix for use in tissue engineering. J Biomed Mater Res A 99: 283-294.

29. Remlinger NT, Czajka CA, Juhas ME, Vorp DA, Stolz DB, et al. (2010) Hydrated xenogeneic decellularized tracheal matrix as a scaffold for tracheal reconstruction. Biomaterials 31: 3520-3526.
30. Zou Y, Zhang Y (2011) Mechanical Evaluation of Decellularized Porcine Thoracic Aorta. J Surg Res .

31. BG, Kojima K, Vacanti CA, Edelman ER (2008) Tissue-engineered endothelial and epithelial implants differentially and synergistically regulate airway repair. Proc Natl Acad Sci USA 105: 7046-7051.
This article was originally published in a special issue, Regenerative Medicine handled by Editor(s). Dr. Lisa M Larkin, University of Michigan, USA. 